\title{
Incidence of Hospital-Admitted Severe Traumatic Brain Injury and In-Hospital Fatality in Norway: A National Cohort Study
}

\author{
N. Andelic ${ }^{a}$ A. Anke ${ }^{b, c}$ T. Skandsen ${ }^{\text {d, e }}$ S. Sigurdardottir ${ }^{f}$ M. Sandhaug ${ }^{g}$ \\ T. Ader ${ }^{h} \quad$ C. Roe ${ }^{a}$ i
}

${ }^{a}$ Department of Physical Medicine and Rehabilitation, Oslo University Hospital, Ulleval, Oslo, ${ }^{\mathrm{b}}$ Division of Rehabilitation, University Hospital of North Norway, and ${ }^{C}$ Faculty of Health Sciences, Institute of Clinical Medicine, University of Troms $\varnothing$, Troms $\varnothing,{ }^{d}$ Department of Physical Medicine and Rehabilitation, St. Olavs University Hospital, and ' Department of Neuroscience, Norwegian University of Science and Technology, Trondheim, fSunnaas Rehabilitation Hospital, Department of Research, Nesoddtangen, 9 Department of Physical Medicine and Rehabilitation, Research Unit, Sørlandet Hospital, Kristiansand, ${ }^{h}$ Department of Physical Medicine and Rehabilitation, Haukeland University Hospital, Bergen, and 'Faculty of Medicine, University of Oslo, Oslo, Norway

\section{Key Words}

Severe traumatic brain injury $\cdot$ Hospital admissions $\cdot$ Adults, epidemiology $\cdot$ Incidence $\cdot$ National cohort study $\cdot$

Case-fatality rate

\begin{abstract}
Aims: The aims of this study were to assess the incidence of hospital-admitted severe traumatic brain injury (TBI) in the adult population in Norway, and to determine whether there were differences in the epidemiological characteristics of severe TBI between rural and urban regions. Methods: A prospective population-based study on adults with severe TBI admitted to the Norwegian Trauma Referral Centres during the 2-year period (2009-2010). The electronic patient register was searched weekly for ICD-10 diagnoses of intracranial injuries (S06.0-S06.9) to identify patients. Severe TBI was defined as lowest unsedated Glasgow Coma Scale Score $\leq 8$ during the first $24 \mathrm{~h}$ after injury. Results: The annual ageadjusted incidence was estimated at 5.2/100,000 in 2009 and $4.1 / 100,000$ in 2010. The highest frequency of hospitalized patients was found among the youngest and the oldest age
\end{abstract}

groups. The most common causes of injury were falls and transport accidents. The highest in-hospital case-fatality rate was found among the oldest patients. There were consistent epidemiological characteristics of severe TBI from both rural and urban regions. Conclusions: The incidence of hospital-admitted patients with severe TBI in this national study supports the declining incidence of TBI reported internationally. No major differences were found in epidemiological characteristics between the urban and rural parts of Norway.

Copyright $\odot 2012$ S. Karger AG, Basel

\section{Introduction}

Traumatic brain injury (TBI), defined as brain injury caused by external trauma, is a worldwide public-health problem, with high mortality rates and a long-term loss of function accompanying the severest injuries [1]. Prevention policies cannot be properly targeted without reliable data on the incidence, demography and external causes of injuries that aid in identifying the high-risk

\section{KARGER \\ Fax +41613061234 \\ E-Mail karger@karger.ch}

www.karger.com (c) 2012 S. Karger AG, Basel

$0251-5350 / 12 / 0384-0259 \$ 38.00 / 0$

Accessible online at:

www.karger.com/ned
Nada Andelic, MD, $\mathrm{PhD}$

Department of Physical Medicine and Rehabilitation

Oslo University Hospital, Ulleval

NO-0424 Oslo (Norway)

Tel. +4791 8179 10, E-Mail nadand@ous-hf.no 
groups [2]. International epidemiological studies have reported changes during the last decades, with decreasing rate trends associated with TBI, incidence, hospitalizations and mortality $[3,4]$. The creation of regional trauma referral systems (level I trauma centres) and the introduction of standardized clinical procedures, such as guidelines that recommend transfer of severe TBI cases to neurosurgical centres irrespective of the need for neurosurgery, has resulted in significant reductions in TBI-associated mortality and morbidity [5]. A major drop in the mortality rate in the USA in trauma patients with severe TBI occurred between 1986 and 1995 [6]. The mortality rates from head injuries in Nordic countries (Denmark, Sweden and Norway) also declined from 1987 to 2000 [7], which is consistent with the trends in the USA [6]. However, a recent review by Stein et al. [8] argued that TBIrelated mortality has been stable over the last decade. Among possible factors that contribute to the stable mortality rates are the changes in epidemiological patterns, such as an increasing number of older patients with severe TBI $[3,9]$. The high fatality rate in this patient population may outweigh the effects of the overall improvement in TBI management [10].

Epidemiological factors and the incidence of TBI in Europe over the last 20 years have been reviewed by Tagliaferri et al. [11]. Only a few studies have included the incidence rate of severe TBI, and there were large variations in the reported rates even among those studies (7.120.0/100,000) [12-15]. However, these studies were not conducted on a national level. Thus, the incidence of severe TBI in Europe is not well known, and more data are needed.

We do not have any reliable estimates of the incidence of hospital-admitted patients with severe TBI in Norway. Approximately $70 \%$ of the population in Norway lives in southern regions while the remaining population is widely dispersed in the central and northern regions of Norway [source: Statistics Norway 2009]. Recently published studies from urban regions in the eastern [16] and western regions of Norway [17] reported inconsistent incidence rates. This inconsistency is likely related to the use of different case definitions (TBI vs. head injury, i.e. external injury to the face, scalp and calvarium, which may or may not be associated with brain injury) but nonetheless limits generalizability $[16,17]$. However, the trends toward a high incidence in the elderly and falls as the main cause of injury were consistent in both studies. A previous study from rural regions of northern Norway was conducted 20 years ago [18] and studies are needed to provide current information on the trends in the inci- dence of severe TBI. The trauma mechanism and subsequent type of injuries along with their severity, as well as the pre-hospital distances, may vary among these regions, with different accompanying demands on the health care system. Thus, accurate documentation of the incidence, risk groups and complications of TBI is imperative for the development of prevention policies and the management of severe TBI.

During 2009 and 2010, the Norwegian Trauma Referral Centres conducted a national multicenter study on severe TBI. Due to the centralization policy reflected in the guidelines [19], this study had a potential to cover the whole population of Norway. The study is of international interest because there are very few previous studies that cover a whole country, and Norway has well-organized public trauma system with a highly developed infrastructure and transportation systems enabling most TBI patients to be transported to a neurosurgical department for definitive treatment [19].

The aims of this part of the study were to assess the incidence of hospital admission for severe TBI in the adult population in Norway and to determine whether there were differences between rural and urban regions in the frequency of severe TBI, age and gender distribution, external causes of injury, substance consumption (drug and alcohol use), injury severity and fatality rates.

\section{Materials and Methods}

\section{Study Region}

In Norway, patients with severe TBI are treated in neuro-intensive care units/neurosurgical departments in the acute phase in accordance with the Nordic adaptation of the Brain Trauma Foundation guidelines [19]. There are four health regions in Norway, each with one defined Trauma Referral Centre: University Hospital of North Norway in the northern region, St. Olavs Hospital in the central region, Haukeland University Hospital in the western region and Oslo University Hospital in the south-eastern region of Norway. All four hospitals have neurosurgical departments. In the western region, there is an additional neurosurgical department at Stavanger University Hospital [19].

The population of adults (age $\geq 16$ years) is $2,143,661$ in the southeast region of Norway; 780,649 in the western region; 530,008 in the central region and 369,809 in the northern region [source: Statistics Norway 2009]. For the purpose of this study, we considered the northern and central regions of Norway as more rural due to long distances between population centres with an adult population density of 3.5 and 9.9 inhabitants $/ \mathrm{km}^{2}$ land area, respectively. The western and southern regions are considered as more urban due to shorter distances between population centres with an adult population density of 19 and 26 inhabitants $/ \mathrm{km}^{2}$ land area, respectively [source: Statistics Norway 2009]. The prehospital emergency medical services are, however, well organized 
in Norway. Severely injured patients are transported directly from the site of injury to the neurosurgical department or stabilized at the local hospitals and transferred thereafter. The transportation system for these patients is based on helicopters and fixed-wing air ambulances [19].

The study is a part of larger prospective population-based multicentre study on adults with severe TBI admitted to neurosurgical departments during the 2-year period from January 2009 to December 2010, where incidence data are collected for all patients and in-depth analysis for the patients filling the criteria for follow-up.

\section{Inclusion Procedure}

The inclusion of patients and the collection of data in the acute phase were performed at the previously mentioned four university hospitals. In each hospital, a regional research coordinator was in charge of the study. The electronic patient register was searched weekly to identify all patients with severe TBI who had been admitted to the Trauma Referral Centres with an acute injury. In addition, a retrospective search through the patient register was performed at the Neurosurgical Department at Stavanger University Hospital for patient admissions in 2009 and the first half of 2010. The data for the second part of 2010 were not available and were therefore estimated from available data.

The patients were evaluated for inclusion if they were $\geq 16$ years old and had ICD-10 diagnosis codes corresponding to intracranial injuries (S06.0-S06.9). Patients residing in Norway, admitted within $72 \mathrm{~h}$ after injury were included if they met the definition of severe TBI. TBI severity was classified according to Glasgow Coma Score (GCS) scores as suggested by Barker-Collo and Feigin [20]. Severe TBI was defined as unsedated (GCS) score $\leq 8$ during the first $24 \mathrm{~h}$ after injury. The GCS scores were recorded in all patients. The ICD-10 diagnoses of intracranial injuries were mainly based on computed tomography (CT) findings. CT scans were performed in all patients.

As we applied predefined exclusion criteria for the follow-up study, patients were excluded if they were injured abroad $(n=5)$, if they had progressive neurological diseases/injuries $(n=19)$, if they had severe psychiatric diseases $(n=11)$ or severe alcohol and/ or narcotics abuse $(n=16)$, if they were homeless $(n=2)$ or if they did not consent $(n=10)$. However, the excluded patients were accounted for in the incidence rate estimates.

\section{Data Registrations}

Each regional coordinator, in collaboration with the project manager (C.R., last author), was responsible for data collection in the acute phase. Regional coordinators participated in a number of videoconference meetings before the start of the study to find a common platform for data collection and to diminish variability of procedures across study regions.

Data registrations were based on medical records and other available clinical information from the stay in the neuro-intensive care units/neurosurgical departments. The registration data comprised the demographic data, external cause of injury (transport accidents, falls, assaults, others/sport injuries), substance consumption at the time of injury (clinical and/or laboratory evaluation) and severity of injury (level of consciousness as assessed by the lowest GCS within the first $24 \mathrm{~h}$ after injury, ICD-10 diagnoses of intracranial injury, accompanying extracranial injuries and death).

Severe Traumatic Brain Injury in Norway
Data Analyses and Statistics

The incidence of hospital-treated adults with severe TBI per 100,000 persons per year was calculated on the basis of the following information:

(a) The number of new hospital-treated adults with severe TBI residing in Norway was used as the numerator.

(b) Demographic data detailing the Norwegian adult population (aged 16 years or older) from Statistics Norway 2009 $(3,824,127)$ and $2010(3,876,857)$ were used as the denominator.

The remaining data are presented as the mean value with standard deviation (SD) and the median value with interquartile range (IQR) or proportions. When comparing genders, a MannWhitney $U$ test was used for continuous variables. The $\chi^{2}$ test for contingency tables was used to detect associations between categorical independent variables. The in-hospital fatality rates were calculated using the following formula: fatal injury/(fatal injury + non-fatal injury) $\times 100$. A significance level of $5 \%$ was used. All statistical analyses were performed with SPSS 16.0 (SPSS Inc., Chicago, Ill., USA). SigmaPlot 11.00 software was used for figures.

\section{Results}

We chose to report incidence over 2 years to illustrate the fluctuation in severe TBI and also to accrue an adequate number for the analysis of urban/rural and agerelated effects.

\section{Annual Incidence Rate of Severe TBI}

Over the 2-year study period, 359 patients residing in Norway with acute severe TBI were recorded, including 199 patients injured in 2009 and 160 patients injured in 2010. The overall incidence rate of severe TBI age-adjusted to the Norwegian adult population in 2009 and 2010 was estimated at 5.2/100,000 and 4.1/100,000, respectively. For the years 2009 and 2010, the age-adjusted annual incidence for males was 8.4/100,000 and 5.6/100,000, and for females 2.0/100,000 for each year. Furthermore, the annual incidence rates in the north/central regions (rural) were 5.9/100,000 and 4.3/100,000, respectively, and in the west/southeast regions (urban) 5.0/100,000 and 4.1/100,000.

Epidemiological data collected on patients included in the follow-up part of the study $(n=278)$ were selected for further analysis. The age and gender distribution of severe TBI is shown in figure 1 . The mean age for the whole population was 46.7 years (SD 21.6), 44.8 years (SD 20.1) for males and 53.2 years (SD 25.5) for females $(\mathrm{p}=0.02)$. The highest frequency of injury was noted in the oldest patients (aged 75 years or older), followed by the youngest patients (aged 16-19 years). Severe TBI occurred at a higher rate in males than females in all age groups. 


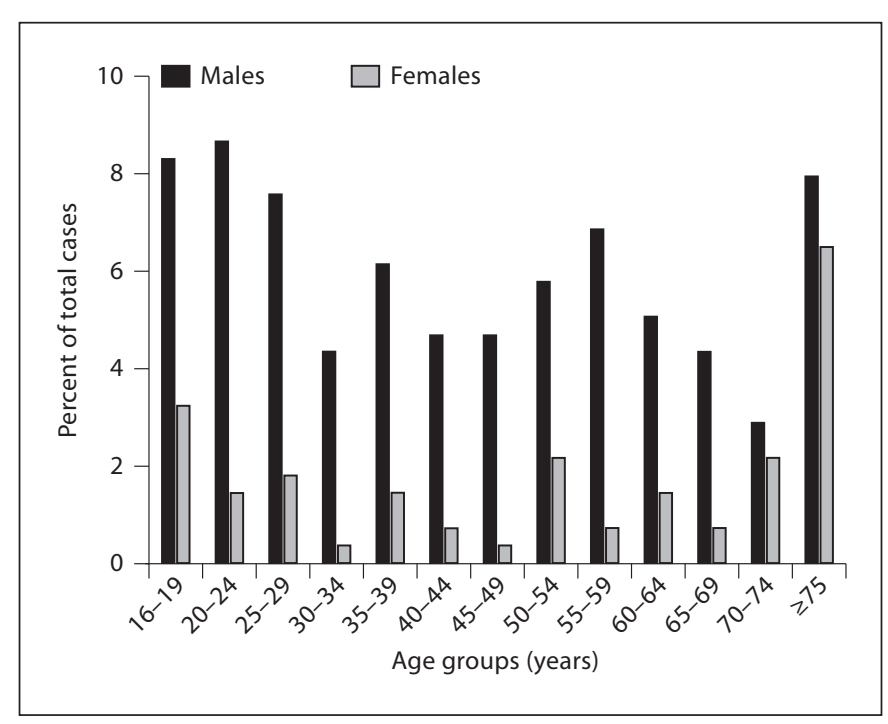

Fig. 1. Percentage of severe TBI by gender in different age groups in Norway 2009-2010.

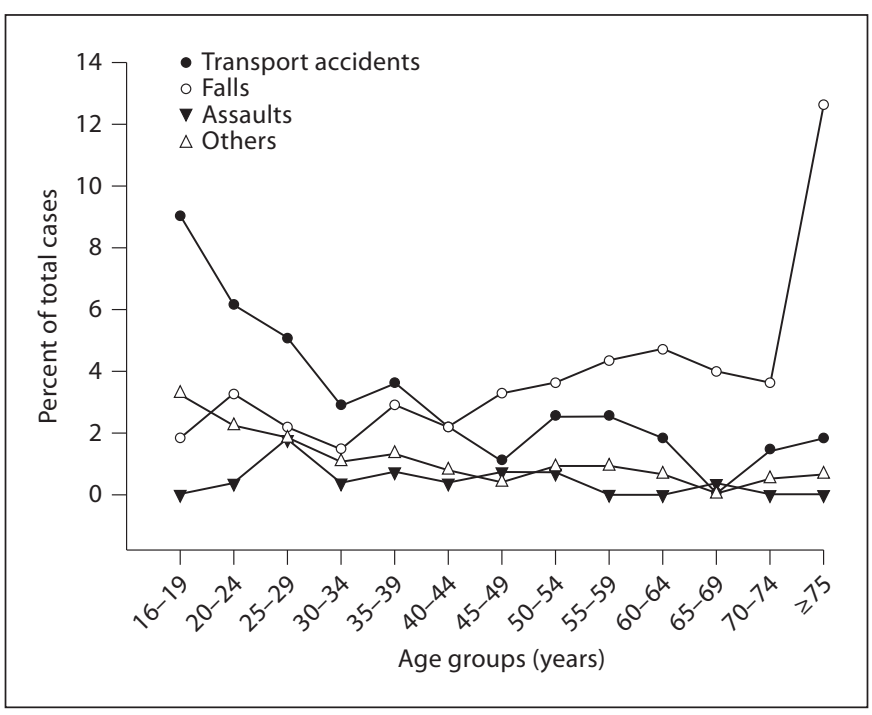

Fig. 2. Percentage of severe TBI by external cause of injury in different age groups in Norway 2009-2010.

The distribution of injuries in the total sample, north/ central (rural) and west/southeast (urban) regions of Norway is presented in table 1.

\section{External Causes of Injury}

Falls were the leading cause of severe TBI and occurred with half of all patients, followed by transport accidents (40\%), assaults (5.5\%) and other injuries (5\%). There was no statistically significant difference in injury
Table 1. Comparison of data from the north/central (rural) and west/southeast (urban) regions in Norway 2009-2010

\begin{tabular}{lllll}
\hline & $\begin{array}{l}\text { North/ } \\
\text { central region } \\
(\mathrm{n}=82)\end{array}$ & $\begin{array}{l}\text { West/south- } \\
\text { east region } \\
(\mathrm{n}=196)\end{array}$ & $\begin{array}{l}\text { Total } \\
\text { value }\end{array}$ & $\begin{array}{l}\text { sample } \\
(\mathrm{n}=278)\end{array}$ \\
\hline Age, mean \pm SD & $47.7 \pm 22.0$ & $46.2 \pm 21.5$ & 0.52 & $46.7 \pm 21.6$ \\
\hline $\begin{array}{l}\text { Gender } \\
\text { Male }\end{array}$ & $64(78)$ & $150(77)$ & 0.78 & $214(77)$ \\
Female & $18(22)$ & $46(23)$ & & $64(23)$ \\
\hline $\begin{array}{l}\text { Cause of injury } \\
\text { Transport accidents }\end{array}$ & $35(43)$ & $76(39)$ & 0.06 & $111(40)$ \\
$\begin{array}{l}\text { Falls } \\
\text { Assaults }\end{array}$ & $37(45)$ & $101(52)$ & & $138(50)$ \\
Others & $2(2)$ & $13(6)$ & & $15(5)$ \\
Severity of injury & $8(10)$ & $6(3)$ & & $14(5)$ \\
$\begin{array}{l}\text { GCS, mean } \pm \text { SD } \\
\text { Multiple ICD-10 }\end{array}$ & $5.4 \pm 2.0$ & $5.2 \pm 2.1$ & 0.35 & $5.3 \pm 2.0$ \\
$\quad$ diagnosis (S06) & $60(73)$ & $149(76)$ & 0.89 & $209(75)$ \\
Isolated TBI & $40(48)$ & $115(59)$ & 0.15 & $155(56)$ \\
Died & $25(31)$ & $55(28)$ & 0.38 & $80(29)$ \\
\hline
\end{tabular}

Figures in parentheses are percentages.

causes with respect to gender. External causes of injury varied with age (fig. 2). TBI hospitalizations associated with falls presented an age peak in the oldest patients and a mean age of 56.8 years (SD 20.2). The highest rate of transport accidents was among the 16- to 19-year age group, and the median age of patients injured by these accidents was 29 years (IQR 31). Among transport accidents, car accidents were the most frequent (52\%) and the median age of patients injured by car accident was 26 years (IQR 18). Motorcycle accidents accounted for $22 \%$ and median patient age in these accidents was 29 years (IQR 25). Pedestrians injured in transport accidents were significantly older, with a median age of 56 years (IQR 48). The assault rate was highest among patients in the 25 - to 29-year age group, and the median age in this population was 35 years (IQR 20). There were no differences concerning the causes of injuries between patients from the north/central (rural) and west/southeast (urban) regions of Norway (table 1).

\section{Substance Consumption}

Evidence of substance use at the time of injury was found in $32 \%$ of the patients. Alcohol was the most frequent substance used (90\%), followed by cannabis and amphetamines. Gender or age differences among pa- 
Table 2. Overview of injury severity as measured by GCS groups and by ICD-10 diagnoses

\begin{tabular}{|c|c|c|c|c|c|c|c|c|c|c|c|}
\hline \multirow[t]{2}{*}{ Severity category } & \multicolumn{10}{|c|}{ ICD-10 diagnoses of intracranial injuries (S06.0-S06.9) } & \multirow{2}{*}{$\begin{array}{l}\text { Total } \\
\text { GCS } \\
\text { sample }\end{array}$} \\
\hline & S06.0 & S06.1 & S06.2 & S06.3 & S06.4 & S06.5 & S06.6 & S06.7 & S06.8 & $\begin{array}{l}\text { multiple } \\
\text { S06.0-S06.9 } \\
\text { diagnoses }\end{array}$ & \\
\hline GCS 3-4 & 3 & 2 & 4 & 1 & 2 & 14 & 2 & 0 & 0 & 96 & $124(45)$ \\
\hline GCS 5-6 & 2 & 0 & 1 & 1 & 1 & 5 & 7 & 0 & 1 & 36 & $54(20)$ \\
\hline Total ICD-10 sample & $6(2)$ & $3(1)$ & $7(3)$ & $5(2)$ & $5(2)$ & $27(10)$ & $11(4)$ & $1(0.3)$ & $2(0.7)$ & $209(75)$ & $276(100)$ \\
\hline
\end{tabular}

Figures in parentheses are percentages.

ICD-10 diagnoses = S06.0 concussion; S06.1 = traumatic cerebral oedema; S06.2 = diffuse brain injury; S06.3 = focal brain injury; S06.4 = epidural haemorrhage; S06.5 = subdural haemorrhage; S06.6 = traumatic subarachnoid haemorrhage; S06.7 = intracranial injury with prolonged coma; S06.8 = other intracranial injuries; S06.9 = intracranial injury, unspecified.

tients with and without reported substance use were not found ( $p=0.60$ and $p=0.50$, respectively). Substance consumption was more frequently identified in the urban, west/southeast region of Norway (36 vs. $23 \%$ ), but a significant statistical difference was not found $(\mathrm{p}=0.13)$. Most commonly, substance consumption was associated with patients injured by assaults (60\%). Forty-one per cent of those injured by falls were under the influence of alcohol or drugs at the time of injury including $28 \%$ of patients in the age group $\geq 60$ years. Twenty-one per cent of those injured in transport accidents were also influenced; $57 \%$ of these patients were younger than 30 years. No substance consumption was found among patients in the age group $\geq 60$ years injured in transport accidents.

\section{Severity of Injury}

The mean value of the lowest GCS score within $24 \mathrm{~h}$ after injury was 5.2 (SD 2.0) with a range of 3-8. Fortyfive per cent of the patients were in the lowest GCS group [3-4] (table 2). Half of the patients in the oldest population had a GCS of $3-4$, and $20 \%$ of the patients had a GCS of 5-6. There were no gender differences regarding injury severity as assessed by the GCS $(p=0.47)$. There were no differences between patients from the north/central (rural) and west/southeast (urban) regions regarding injury severity $(\mathrm{p}=0.36)$.

Seventy-five per cent of the patients suffered from at least two intracranial injuries as assessed by ICD-10 diagnoses (table 2). There were no statistically significant differences in number of the ICD-10 diagnoses with respect to gender $(\mathrm{p}=0.29)$, age groups $(\mathrm{p}=0.68)$ and regional distribution $(\mathrm{p}=0.54)$.
Isolated severe TBI (ICD-10 diagnoses S06.0-S06.9) occurred in $56 \%$ of the patients. The remaining patients had severe TBI with at least one accompanying injury. There were no statistically significant gender or regional differences between these two groups $(p=0.19$ and $p=0.11$, respectively). Ten per cent of patients were presented with isolated subdural haemorrhage, and the majority of those patients were 50 years old or older (90\%). Multiple injuries (TBI and accompanying injuries) occurred more often in younger patients (50\% of patients aged $16-39$ years, $\mathrm{p}=$ $0.01)$ and patients injured in transport accidents $(71 \%, \mathrm{p}=$ 0.001 ). Of those injured by falls, $26.5 \%$ suffered from accompanying injuries.

\section{In-Hospital Fatality Rate}

Eighty patients (29\%) died after hospital admission, giving an average in-hospital fatality rate of 29 per 100 hospitalized patients included in the study. A majority of patients died within $48 \mathrm{~h}$ after admission (73\%), and 15\% died 3-7 days after admission (the median length of stay in acute hospital was 12 days, IQR 14). The percentage of fatal outcomes was highest in the oldest patients (fig. 3). Sixty per cent of patients aged $\geq 75$ years as compared with $16 \%$ of patients aged $16-29$ years died after hospital admission. There were no statistically significant gender $(\mathrm{p}=0.87)$ or regional differences in fatality rates $(\mathrm{p}=$ 0.38 ). Of the patients injured by falls, $34 \%$ died, as compared with $24 \%$ of those injured in transport accidents. Of 124 patients with the lowest GCS of 3-4, 51\% died. In addition, $12 \%$ in GCS group of $5-6$ and $10 \%$ in GCS group 7-8 died. 


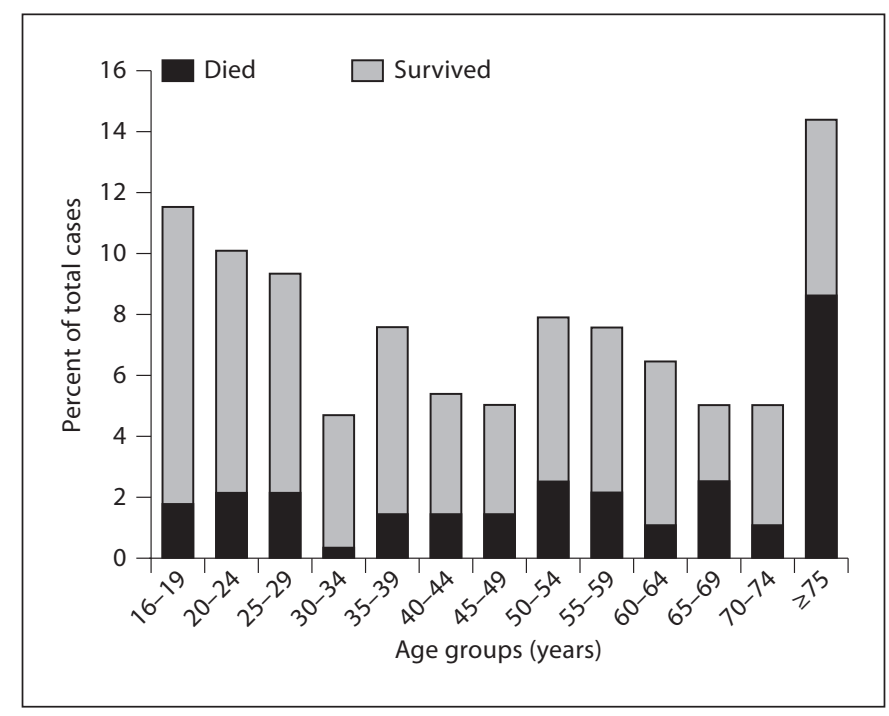

Fig. 3. Percentage of severe TBI-related hospital deaths and survivors by age groups 2009-2010.

\section{Discussion}

\section{Annual Incidence Rate of Severe TBI}

The incidence rates estimated in this study were lower than in other international studies on severe TBI. In the literature, the annual incidence rate for hospital-treated severe TBI is between 7 and 20/100,000 persons [12-15]. A Danish study assessed patients admitted to emergency departments and intensive care units in 1988 and estimated an incidence rate of $22.6 / 100,000$ persons for severe TBI defined as post-traumatic amnesia $24 \mathrm{~h}$ to 7 days, and 7.1/100,000 for those with post-traumatic amnesia $>7$ days [13]. A Swiss study assessed severe TBI patients treated with neurosurgery for brain injuries in 1987 and estimated an incidence rate of 20/100,000 [12]. A study by Masson et al. [15] examined patients admitted to the hospital with prolonged coma (GCS $\leq 8$ before sedation) in 1996 and found an incidence rate of 8.5/100,000. A German study assessed severe TBI in an urban area of 1,000,000 inhabitants over 10 years (from 1990 to 1999) and found an estimated annual incidence of 7.3/100,000 [21].

The differences in incidence rates between the present and previous studies $[2,5,6,22]$ can probably be explained by the general decrease in the incidence of TBI during preceding decades and discrepancies between studies due to the TBI case identification and definitions, as mentioned in the introduction. Furthermore, the present study population comprises only adults hospitalized with severe TBI as assessed by GCS $\leq 8$. However, our rates are comparable with recent Norwegian incidence rate estimates for hospital-treated severe TBI from Oslo $(5 / 100,000)$ [16] and the central region of Norway $(4 / 100,000)[23]$. The rates are also comparable with data from the Norwegian Patient Registry when only ICD-10 diagnoses defining severe TBI (brain swelling, contusions and haemorrhages in patients hospitalized $>1$ week) are included.

The male/female ratio and mean age in this study are in accordance with other previous European studies [14] along with more recently published Austrian [24] and Dutch studies [10] that included adult patients. Recent studies have emphasized the increasing number of elderly individuals with severe TBI, and the results of this study support those findings [25].

\section{External Causes of Injury}

Falls were the most common external cause of injury in this study and are the most frequent causes of severe TBI in older patients. This result is consistent with previous Norwegian studies, studies from North Europe [25, 26] and reports from the USA [27]. Fall-related severe TBI cases have steadily increased since the 1990s, especially among older adults $[15,27]$ because of the increase in age in the overall population of developed countries. Predisposing factors for falls in elderly individuals include comorbidities, impaired balance, effects of alcohol consumption, and the use of multiple medications that may cause dizziness [27]. The use of oral anticoagulants at the time of injury and advanced age are associated with more severe injuries [28]. Low-energy falls, such as falling from a standing height, are reported to lead to a high proportion of severe TBI among these patients [25]. As in other countries in Western Europe, the proportion of older adults increases in the Norwegian population. The number of people older than 67 years in Norway is expected to increase from 0.6 million in 2009 to 1.5 million in 2060 [source: Statistics Norway]. Unless more effective fall-related prevention strategies are implemented, severe TBI caused by falls in older people will become an even larger health problem in the future.

Transport accidents are the second-leading external cause of injury, and the rates were highest among the youngest patients in this study. A high frequency of car and motorcycle accidents was found among young patients as well as, frequently, consumption of drugs or alcohol. These results are in accordance with international studies [27]. Transport accident-related severe TBI cases have decreased since the 1990s both in Europe [11, 18] 
and the USA [29]. These findings may reflect the effectiveness of preventive efforts that have been introduced during that period. However, the fact that the median age in the study population injured in these accidents is 28.5 years indicates that preventive efforts should be reinforced in order to reduce this substantial public health problem among young adults.

Assaults were more frequent in the southern region of Norway. It is well known that these injuries are more frequent in highly populated regions and areas with high rates of substance consumption, particularly drug and alcohol consumption [30]. Substance use among patients injured by assaults was found only in male patients in this study. Drug and alcohol consumption are frequent among assaulted males [11].

\section{Substance Consumption}

The substance consumption rate found in this study was within the range of those reported in previous studies $[11,18]$. This study also confirms that alcohol is the most common substance used in the TBI population [11, 31]. Frequent substance consumption was also found in older patients injured by falls, confirming that drug and alcohol influence is a predisposing factor for fall-related TBI in geriatric populations [27]. The current drinking patterns among the elderly suggest that the use of alcohol gradually declines with age after 60 although regular alcohol consumption is rather common also in this group. A trend towards increasing alcohol consumption in the general Norwegian population was observed during the last decades as a result of an increased number of regular drinkers [32]. Norway is, however, in the lower range of international statistics on alcohol consumption as compared to other Western countries [33]. This could be explained by limitation in the availability of alcohol, as well as the high taxations on alcoholic beverages in Norway [31].

\section{Severity of Injury}

The GCS is the most commonly used indicator of initial TBI severity in clinical trials and is often used in epidemiological studies to determine TBI severity [34]. However, there are a few updated epidemiological studies with study populations including only severe TBI cases (GCS $\leq 8)$. The mean of the lowest GCS within $24 \mathrm{~h}$ after injury of 5.3 confirmed that patients in this study suffered from severe TBI. In the previously mentioned Austrian and Dutch studies, which described hospital-based epidemiology of severe TBI, a similar GCS mean value is reported $[10,24]$.

Severe Traumatic Brain Injury in Norway
The number of ICD-10 diagnoses confirmed the severity and extension of intracranial injuries in this population. Roughly half of the patients had accompanying injuries, and these results are in accordance with other studies [21]. As expected, these injuries were more often observed in high-energy events such as transport accidents [10].

\section{In-Hospital Fatality Rate}

Severe-TBI fatality rates after admission to hospital are $25-40 \%[21,22]$. In the present study, a fatal outcome was found in $29 \%$ of the patients. There were no statistically significant regional differences despite the longer transportation distances in the north/central regions of Norway when compared with the southern region. The lack of differences probably reflects the implementation of guidelines for pre-hospital management of severe TBI adapted to the infrastructure of the Nordic countries with the overall goal of quickly bringing circulatory and respiratory stable patients to regional neurosurgical departments where they can receive definitive treatment [19].

In-hospital fatality rates reflect the severity of TBI assessed in this study. A low GCS (score of 3) correlates with a high fatality rate and this result is consistent with previous studies [35]. The high proportion of early mortality (within $48 \mathrm{~h}$ after admission) was in accordance with other studies [35]. The highest fatality rate was found in the oldest patient group, and these results are in accordance with previous studies $[3,16,17,27]$. There is a general consensus that the probability of poor TBI outcome increases with age [36] even though patients of advanced age tend to have less severe TBI and overall injuries [37]. The presence of a comorbid cardiac condition and coagulopathy significantly increases overall mortality in older adults [38]. According to Brazinova et al. [39], such evidence could lead to a policy not to treat older patients with severe TBI as aggressively as younger patients, which may have occurred in this study as well.

\section{Strengths and Limitation of the Study}

This national study provides greatly generalizable demographics and injury severity to adults suffering severe TBI in Norway. This study is one of the few studies to include prospectively obtained national data on severe TBI. Children were omitted from the study because their health care system in Norway differs from that for the adult population and because of the difficulties in classifying and evaluating clinical documentation in this population in connection with early management of TBI 
[40]. Including children would probably have added 0.3 to the total annual incidence of severe TBI if we used the 2005 incidence estimates from the Oslo population [16]. Furthermore, we did not search for patients who had not been transferred from a local hospital, which typically may be the case for older patients with a poor prognosis. Hence, a slight underestimation of the overall hospital admission rate is assumed. The study does not account for patients who died at the accident site or during transportation to hospital because the study was designed to assess the incidence of hospital-admitted TBI and inpatient mortality. On the other hand, due to the prospective design and congruent inclusion criteria, the characteristics of the surviving patients with severe TBI are precisely documented. However, data collection from the Stavanger University Hospital was retrospective, which may have influenced the accuracy of the inclusion procedure. Additionally, the data for the second part of 2010 were not available and were estimated. The estimates were controlled in relation to the data from the Norwegian Patient Registry and the estimates were found to be comparable with the number of hospital-treated patients with ICD-10 diagnoses indicated severe TBI (brain swelling, contusions and haemorrhages, hospitalized $>1$ week) at Stavanger University Hospital. Another important limitation of the study is the definition of rural and urban regions which cover the population size and density, and distances between population centres, but not land use, employment opportunities and socio-cultural characteristics.
In this study, the diagnoses of severe TBI were based on GCS. Thus the severity categories are probably biased as GCS scores may be influenced by drug and alcohol use at the time of injury, as well as the use of sedatives [10,30]. However, the intracranial pathology as assessed by ICD10 diagnoses still was indicative of severe brain damage in this patient population. The diagnoses of crushing and unspecified injuries to the head (S07-S09) also indicated intracranial injuries, but they were not used in this study as these diagnoses are seldom used in Norway. Although this study was performed before standards for a population-based TBI incidence studies suggested by BarkerCollo and Feigin [20] were available, it appears to be in line with the majority of their 'core' criteria.

\section{Acknowledgments}

The authors would like to thank the Neurosurgical Department of Stavanger University Hospital for all their help with registrations from their patient registers. Thanks to Unn Manskow, Beate Holmquist Karlsen and Stine Borgen Lund for valuable help with data collection. Special thanks are extended to the Norwegian Patient Registry for personal communication/overview of the ICD-10 diagnoses for patients admitted to the Norwegian hospitals in 2009. This study was supported by grants from the Norwegian Research Council.

\section{Disclosure Statement}

The authors report no conflicts of interest.

\section{References}

1 Ragnarsson KT: Traumatic brain injury research since the 1998 NIH Consensus Conference: accomplishments and unmet goals. J Head Trauma Rehabil 2006;21:379-387.

-2 Colantonio A, Croxford R, Farooq S, Laporte A, Coyte PC: Trends in hospitalization associated with traumatic brain injury in a publicly insured population, 1992-2002. J Trauma 2009;66:179-183.

-3 Flanagan SR, Hibbard MR, Gordon WA: The impact of age on traumatic brain injury. Phys Med Rehabil Clin N Am 2005;16:163-177.

4 Steudel WI, Cortbus F, Schwerdtfeger K: Epidemiology and prevention of fatal head injuries in Germany - trends and the impact of the reunification. Acta Neurochir (Wien) 2005; 147:231-242.

5 Kay A, Teasdale G: Head injury in the United Kingdom. World J Surg 2001;25:1210-1220.

6 Kelly DF, Becker DP: Advances in management of neurosurgical trauma: USA and Canada. World J Surg 2001;25:1179-1185.
-7 Sundstrom T, Sollid S, Wentzel-Larsen T, Wester K: Head injury mortality in the Nordic countries. J Neurotrauma 2007;24:147153.

8 Stein SC, Georgoff P, Meghan S, Mizra K, Sonnad SS: 150 years of treating severe traumatic brain injury: a systematic review of progress in mortality. J Neurotrauma 2010; 27:1343-1353.

-9 Gerber LM, Ni Q, Hartl R, Ghajar J: Impact of falls on early mortality from severe traumatic brain injury. J Trauma Manag Outcomes 2009;3:9.

10 Andriessen TM, Horn J, Franschman G, et al: Epidemiology, severity classification, and outcome of moderate and severe traumatic brain injury: a prospective multicenter study. J Neurotrauma 2011;28:2019-2031.

-11 Tagliaferri F, Compagnone C, Korsic M, Servadei $\mathrm{F}$, Kraus J: A systematic review of brain injury epidemiology in Europe. Acta Neurochir (Wien) 2006;148:255-268.
12 Annoni JM, Beer S, Kesselring J: Severe traumatic brain injury - epidemiology and outcome after 3 years. Disabil Rehabil 1992;14: 23-26.

13 Engberg A: Severe traumatic brain injury epidemiology, external causes, prevention, and rehabilitation of mental and physical sequelae. Acta Neurol Scand Suppl 1995;164: $1-151$.

14 Masson F, Thicoipe M, Aye P, et al: Epidemiology of severe brain injuries: a prospective population-based study. J Trauma 2001;51: 481-489.

15 Masson F, Thicoipe M, Mokni T, Aye P, Erny P, Dabadie P: Epidemiology of traumatic comas: a prospective population-based study. Brain Inj 2003; 17:279-293.

- 16 Andelic N, Sigurdardottir S, Brunborg C, Roe C: Incidence of hospital-treated traumatic brain injury in the Oslo population. Neuroepidemiology 2008;30:120-128. 
-17 Heskestad B, Baardsen R, Helseth E, Romner $\mathrm{B}$, Waterloo K, Ingebrigtsen T: Incidence of hospital referred head injuries in Norway: a population based survey from the Stavanger region. Scand J Trauma Resusc Emerg Med 2009;17:6.

18 Ingebrigtsen T, Mortensen K, Romner B: The epidemiology of hospital-referred head injury in northern Norway. Neuroepidemiology 1998;17:139-146.

19 Sollid S, Sundstrom T, Ingebrigtsen T, Romner B, Wester K: Organisation of traumatic head injury management in the Nordic countries. Emerg Med J 2009;26:769-772.

20 Barker-Collo SL, Feigin VL: Capturing the spectrum: suggested standards for conducting population-based traumatic brain injury incidence studies. Neuroepidemiology 2009; 32:1-3.

-21 Maegele M, Engel D, Bouillon B, et al: Incidence and outcome of traumatic brain injury in an urban area in Western Europe over 10 years. Eur Surg Res 2007;39:372-379.

-22 Jennett B: Epidemiology of head injury. J Neurol Neurosurg Psychiatry 1996;60:362369.

23 Skandsen T: Moderate and Severe Traumatic Brain Injury. Norwegian University of Science and Technology, Trondheim, 2010.

24 Rosso A, Brazinova A, Janciak I, Wilbacher I, Rusnak M, Mauritz W: Severe traumatic brain injury in Austria II: epidemiology of hospital admissions. Wien Klin Wochenschr 2007;119:29-34.

-25 Koskinen S, Alaranta H: Traumatic brain injury in Finland 1991-2005: a nationwide register study of hospitalized and fatal TBI. Brain Inj 2008;22:205-214.
26 Hukkelhoven CW, Steyerberg EW, Farace E, Habbema JD, Marshall LF, Maas AI: Regional differences in patient characteristics, case management, and outcomes in traumatic brain injury: experience from the tirilazad trials. J Neurosurg 2002;97:549-557.

27 Coronado VG, Xu L, Basavaraju SV, et al: Surveillance for traumatic brain injury-related deaths - United States, 1997-2007. MMWR Surveill Summ 2011;60:1-32.

28 Franko J, Kish KJ, O’Connell BG, Subramanian S, Yuschak JV: Advanced age and preinjury warfarin anticoagulation increase the risk of mortality after head trauma. J Trauma 2006;61:107-110.

29 Langlois JA, Rutland-Brown W, Wald MM: The epidemiology and impact of traumatic brain injury: a brief overview. J Head Trauma Rehabil 2006;21:375-378.

30 Bruns J, Jr, Hauser WA: The epidemiology of traumatic brain injury: a review. Epilepsia 2003;44(suppl 10):2-10.

31 Andelic N, Jerstad T, Sigurdardottir S, Schanke AK, Sandvik L, Roe C: Effects of acute substance use and pre-injury substance abuse on traumatic brain injury severity in adults admitted to a trauma centre. J Trauma Manag Outcomes 2010;26;4-6.

32 Norwegian Institute for Alcohol and Drug Research: Alcohol and Drugs in Norway. Oslo, Norwegian Institute for Alcohol and Drug Research 2006, pp 28-39.
33 Strand BH, Steiro A: Alcohol consumption, income and education in Norway, 19932000 (in Norwegian). Tidsskr Nor Laegeforen 2003;123:2849-2853.

-34 Saatman KE, Duhaime AC, Bullock R, Maas AI, Valadka A, Manley GT: Classification of traumatic brain injury for targeted therapies. J Neurotrauma 2008;25:719-738.

35 Lieberman JD, Pasquale MD, Garcia R, Cipolle MD, Mark LP, Wasser TE: Use of admission Glasgow Coma Score, pupil size, and pupil reactivity to determine outcome for trauma patients. J Trauma 2003;55:437-442.

36 Mushkudiani NA, Engel DC, Steyerberg EW, et al: Prognostic value of demographic characteristics in traumatic brain injury: results from the IMPACT study. J Neurotrauma 2007;24:259-269.

-37 Susman M, DiRusso SM, Sullivan T, et al: Traumatic brain injury in the elderly: increased mortality and worse functional outcome at discharge despite lower injury severity. J Trauma 2002;53:219-223.

38 Thompson HJ, McCormick WC, Kagan SH: Traumatic brain injury in older adults: epidemiology, outcomes, and future implications. J Am Geriatr Soc 2006;54:1590-1595.

-39 Brazinova A, Mauritz W, Leitgeb J, et al: Outcomes of patients with severe traumatic brain injury who have Glasgow Coma Scale scores of 3 or 4 and are over 65 years old. J Neurotrauma 2010;27:1549-1555.

-40 Falk AC, Klang B, Paavonen EJ, von Wendt $\mathrm{L}$ : Current incidence and management of children with traumatic head injuries: the Stockholm experience. Dev Neurorehabil 2007;10:49-55. 